\title{
trkA Is Expressed in Nociceptive Neurons and Influences Electrophysiological Properties via Nav1.8 Expression in Rapidly Conducting Nociceptors
}

\author{
Xin Fang, ${ }^{1}$ Laiche Djouhri, ${ }^{1}$ Simon McMullan, ${ }^{2}$ Carol Berry, ${ }^{1}$ Kenji Okuse, ${ }^{3}$ Stephen G. Waxman, ${ }^{4}$ and Sally N. Lawson ${ }^{1}$ \\ ${ }^{1}$ Department of Physiology, Medical School, University of Bristol, Bristol BS8 1TD, United Kingdom, ${ }^{2}$ Hypertension and Stroke Research Laboratory, \\ University of Sydney, Sydney 2065, Australia, ${ }^{3}$ Department of Biology, University College London, London WC1E 6BT, United Kingdom, and ${ }^{4}$ Department \\ of Neurology, Yale University School of Medicine, New Haven, Connecticut 06510
}

To test the hypothesis that trkA (the high-affinity NGF receptor) is selectively expressed in nociceptive dorsal root ganglion (DRG) neurons, we examined the intensity of trkA immunoreactivity in single dye-injected rat DRG neurons, the sensory receptor properties of which were identified in vivo with mechanical and thermal stimuli. We provide the first evidence in single identified neurons that strong trkA expression in DRGs is restricted to nociceptive neurons, probably accounting for the profound influence of NGF on these neurons. Furthermore, we demonstrate that trkA expression is as high in rapidly conducting $(\mathrm{A} \alpha / \beta)$ as in more slowly conducting $(\mathrm{A} \delta$ and $\mathrm{C})$ nociceptors. All A $\alpha / \beta$ low-threshold mechanoreceptors (LTMs) are trkA negative, although weak but detectable trkA is present in some $\mathrm{C}$ and $\mathrm{A} \delta$ LTMs.

NGF can influence electrophysiological properties of DRG neurons, probably by binding to trkA. We found positive correlations for single identified $\mathrm{A} \alpha / \beta$ (but not $\mathrm{C}$ or $\mathrm{A} \delta$ ) nociceptors between trkA immunocytochemical intensity and electrophysiological properties typical of nociceptors, namely long action potential and afterhyperpolarization durations and large action potential amplitudes. Furthermore, for $A \alpha / \beta$ (not $\mathrm{C}$ or $\mathrm{A} \delta$ ) nociceptors, trkA intensity is inversely correlated with conduction velocity. Similar relationships, again only in $\mathrm{A} \alpha / \beta$ nociceptors, between electrophysiological properties and trkA expression exist for sodium channel Nav1.8 but not Nav1.9 immunoreactivities. These findings suggest that in $\mathrm{A} \alpha / \beta$ nociceptors, influences of NGF on expression levels of Nav1.8 are related to, and perhaps limited by, expression levels of trkA. This view is supported by a positive correlation between immuno-intensities of trkA and Nav1.8 in A-fiber, but not C-fiber, nociceptors.

Key words: NGF; pain; dorsal root ganglion (DRG); conduction velocity; action potential; sodium channel

\section{Introduction}

Sensory [dorsal root ganglion (DRG)] neurons depend on nerve growth factor (NGF) for survival during development (Goedert et al., 1984) and for maintenance of aspects of their adult nociceptive phenotype (Mendell, 1999). For example, NGF influences action potential (AP) duration in A-fiber nociceptors in rat DRGs early postnatally (Ritter et al., 1991) and in adults (Djouhri et al., 2001). NGF binds to two types of receptor on DRG neurons: the low-affinity receptor p75 (Casaccia-Bonnefil et al., 1999) and the high-affinity receptor tyrosine kinase A (trkA) (Barbacid, 1994), through which NGF exerts its main influence on sensory neurons (Wiesmann and de Vos, 2001). trkA is expressed in a subgroup of DRG neurons that is assumed to be nociceptive, based on indirect evidence including (1) their relatively small size; (2) trkA expression in primary afferent fibers mainly in superficial dorsal horn

Received Jan. 18, 2005; revised April 1, 2005; accepted April 4, 2005.

This work was supported by Biotechnology and Biological Sciences Research Council and Wellcome grants to S.N.L. and by a Bristol University Studentship to X.F. We thank L. F. Reichardt for the gift of anti-trkA antibody and B. Carruthers for technical assistance.

Correspondence should be addressed to Prof. Sally N. Lawson, Department of Physiology, Medical School, University of Bristol, University Walk, Bristol BS8 1TD, UK. E-mail: Sally.Lawson@bristol.ac.uk.

DOI:10.1523/JNEUROSCI.0249-05.2005

Copyright $\odot 2005$ Society for Neuroscience $\quad$ 0270-6474/05/254868-11\$15.00/0
(Averill et al., 1995; Molliver et al., 1995), a region associated with nociceptive input; and (3) high trkA coexpression with calcitonin gene-related peptide (Averill et al., 1995) and substance P (Kashiba et al., 1996), which are expressed mainly in nociceptive DRG neurons (Lawson et al., 1997, 2002). However, some smallmedium sized neurons are low-threshold mechanoreceptors (LTMs), and some medium-large sized neurons are nociceptors (Fang et al., 2002; Djouhri et al., 2003a). We therefore examined whether trkA is present in all nociceptors and/or is limited to nociceptors.

Because NGF exerts its main effects on sensory neurons through trkA, we hypothesized that the influence of NGF on their electrophysiological properties may depend on their trkA expression levels. We therefore examined in rat DRG neurons whether electrophysiological properties typical of nociceptors are related to trkA immunocytochemical intensity and found these to be related only in rapidly conducting $(\mathrm{A} \alpha / \beta)$ nociceptive neurons that may contribute to sharpness perception, first mechanical pain, and rapid withdrawal responses (for review, see Djouhri and Lawson, 2004).

These relationships could result from the influence of NGF on $\mathrm{Na}^{+}$channel expression. Two TTX-resistant $\mathrm{Na}^{+}$channels, Nav1.8 and Nav1.9, are expressed mainly in nociceptors and are 
associated with their electrophysiological properties: Nav1.8 with high AP amplitude and long AP duration (Renganathan et al., 2001; Djouhri et al., 2003b) and Nav1.9 with AP duration (DibHajj et al., 1998b; Fang et al., 2002). Because NGF (via trkA) regulates Nav1.8 expression (Black et al., 1997; Dib-Hajj et al., 1998a), whereas glial cell line-derived neurotrophic factor (GDNF) regulates both Nav1.8 and Nav1.9 expression in DRG neurons (Fjell et al., 1999; Cummins et al., 2000), and because there is higher Nav1.8 than Nav1.9 immunoreactivity in A-fiber nociceptors (Fang et al., 2002; Djouhri et al., 2003b), we hypothesized that relationships between trkA expression levels and electrophysiological properties in $A \alpha / \beta$ nociceptors might result primarily from trkA expression levels limiting the influence of NGF on Nav1.8 expression. If so, relationships between electrophysiological properties and expression of Nav1.8 (but not Nav1.9) should resemble those between electrophysiological properties and trkA intensity in these neurons. We therefore studied $\mathrm{Na}^{+}$ channel expression in nociceptors that were classified separately into $\mathrm{A} \delta$ and $\mathrm{A} \alpha / \beta$ subgroups to determine the relationship between their electrophysiological properties and immunoreactivity.

\section{Materials and Methods}

Animal preparation. Experimental procedures complied throughout with Home Office (UK) guidelines. Animal preparation was as described previously (Fang et al., 2002). Briefly, young adult Wistar rats (female; 6-7 weeks of age; $160-180 \mathrm{~g}$ ) were deeply anesthetized with sodium pentobarbitone (70-80 mg/kg, i.p.) and maintained areflexic throughout. They were tracheotomized and artificially ventilated. The left external jugular vein and carotid artery were cannulated to allow supplementary anesthetic at regular intervals and to monitor blood pressure, respectively. After a laminectomy, the left L3-L6 DRGs were exposed, and a liquid paraffin pool was constructed using silicone dental impression paste Xantopren (Hanau, Germany) VL plus. The dura over the spinal cord was opened, and the dorsal root of the DRG under study was cut close to its entry to the spinal cord and placed over a pair of platinum stimulating electrodes.

Intracellular recording. Just before recording, a muscle relaxant (pancuronium bromide; $0.6 \mathrm{mg} / \mathrm{kg}$, i.v.) was administered, preceded by 10 $\mathrm{mg} / \mathrm{kg}$ anesthetic. These same doses of muscle relaxant and anesthetic were subsequently given together at regular intervals (approximately hourly). The paraffin pool temperature near the DRG was maintained at $\sim 30^{\circ} \mathrm{C}$ (range, $28.5-32^{\circ} \mathrm{C}$ ). Intracellular voltage recordings from DRG neuronal somata were made with sharp glass microelectrodes filled with a fluorescent dye: $50 \mathrm{mg} / \mathrm{ml}$ Lucifer yellow CH (Sigma, St. Louis, MO) in $0.1 \mathrm{~m} \mathrm{LiCl}$ (Stewart, 1978), $6 \mathrm{mg} / \mathrm{ml}$ ethidium bromide (Sigma) in $1 \mathrm{M}$ $\mathrm{KCl}$ (LePecq and Paoletti, 1967), or 3\% cascade blue (Molecular Probes, Eugene, OR) in $0.1 \mathrm{~m} \mathrm{LiCl}$ (Whitaker et al., 1991). Cell penetrations were as described previously (Lawson et al., 1997). After penetration, the dorsal root was stimulated with a rectangular pulse $(0.03 \mathrm{~ms}$ for A-fiber neurons, $0.3 \mathrm{~ms}$ for C-fiber neurons) up to twice threshold voltage for evoking a somatic AP. Before stimulation of the receptive field, the presence of any spontaneous/ongoing activity was recorded, usually for 1-2 min.

Conduction velocity. Conduction velocity (CV) excluding utilization time was calculated as described previously (Djouhri and Lawson, 2001); the conduction distance was 4-14 mm. Each neuron was classified by its $\mathrm{CV}$, according to dorsal root $\mathrm{CV}$ boundaries determined previously in female rats of the same weight (Fang et al., 2002), as $\mathrm{C}(<0.8 \mathrm{~m} / \mathrm{s}), \mathrm{C} / \mathrm{A} \delta$ $(0.8-1.5 \mathrm{~m} / \mathrm{s}$; included in the $\mathrm{A} \delta$ group unless stated otherwise), $\mathrm{A} \delta$ $(1.5-6.5 \mathrm{~m} / \mathrm{s})$, or $\mathrm{A} \alpha / \beta(>6.5 \mathrm{~m} / \mathrm{s})$.

Identification of sensory receptive properties. Details of methods used for identifying sensory receptive properties were as described previously (Fang et al., 2002). In brief, stimuli were applied to the left hindlimb and flank. These were first nonnoxious (brush, tapping, light touch, vibration) stimuli. If no response to nonnoxious stimuli was seen, noxious stimuli were applied including high-intensity mechanical stimulation with needle, forceps (fine and/or toothed), and thermal stimulation (cooling by a brief localized spray of ethyl chloride and/or heating with water $>50^{\circ} \mathrm{C}$ ).

Neurons responding to nonnoxious mechanical stimuli were classified as LTMs. A $\alpha / \beta$ LTMs included muscle spindle units and cutaneous units: rapidly adapting, slowly adapting, guard hair, or field units. Slowly conducting LTMs included A $\delta$ down hair (D hair) units and C-fiber LTM units (C LTMs). Neurons responding only, or better, to noxious stimuli were classed as nociceptors. Nociceptors included high-threshold mechanoreceptors (HTMs), polymodal, mechano-heat units, and mechanocold units (see below for properties).

Nociceptors that responded to mechanical stimuli were subdivided into those with superficial (probably epidermal or at the border of epidermis and dermis), dermal, or subcutaneous receptive fields as follows. Neurons that responded to needle pressure and pinch of superficial tissues with fine forceps were classed as having superficial receptive fields. Receptive fields of neurons that did not respond to stimulation of superficial tissues but did respond to squeeze of a fold of skin tissue including dermis were classed as dermal. Receptive fields of neurons that failed to respond to the above stimuli but responded to squeezing across the foot or whole leg or pressure to deeper tissues including deep fascia, muscle, and associated connective tissue and periosteum were said to be subcutaneous. A-fiber nociceptors with dermal or subcutaneous receptive fields were combined and categorized as deep.

HTM units included units with superficial or dermal receptive fields that responded to noxious mechanical stimuli but not to noxious thermal stimuli. Because heat penetration into subcutaneous tissues is poor, nociceptive units with such receptive fields were not tested with thermal stimuli. Furthermore, heat stimuli may not penetrate adequately to the terminals of all dermal units. Nonetheless, subcutaneous and dermal nociceptors that did not respond to noxious heat were included in the HTM group in this paper. Moderate pressure units with superficial receptive fields responded weakly to moderate pressure but much better to both needle and stronger pressure; thus, they encode into the noxious range and are classed as nociceptors (Burgess and Perl, 1967). In the present study, they are classed as a subgroup of the A-fiber HTM units.

C-fiber units that responded to noxious mechanical stimuli and also promptly to a single brief application of noxious heat were called $\mathrm{C}$ polymodal units if they had superficial receptive fields and mechano-heat units if they had dermal receptive fields. C- and A-fiber mechano-cold units responded to both noxious mechanical and to cooling stimuli. Although in other studies in this laboratory, small numbers $(\sim 2 \%)$ of A-fiber nociceptive units responded to heat (Djouhri and Lawson, 2004), none of those in the present study responded to heat.

Unresponsive units did not respond to any of the above stimuli. They may include some so-called "silent nociceptors" or units with inaccessible receptive fields (Djouhri et al., 2003b). Unresponsive units with C fibers have similar electrophysiological properties to nociceptive units within the same CV range in both guinea pig (Djouhri et al., 1998) and rat (our unpublished observations). In this paper, therefore, the term nociceptor-type units included C-unresponsive units $(n=9)$ plus all nociceptive units with $\mathrm{C}$ fibers $(n=12)$ and A fibers $(\mathrm{A} \delta, n=15 ; \mathrm{A} \alpha / \beta$, $n=23$ ). Proportions of $\mathrm{C}$-fiber neurons that are unresponsive are hard to assess in this preparation, because it is easy to lose these recordings in the longer process of testing many different stimuli on all tissues. A-fiber unresponsive units were excluded unless specifically mentioned.

Neuronal labeling. Methods for labeling of neuronal somata have been described in detail previously (Fang et al., 2002). For each neuron, after completion of recordings, fluorescent dye was electrophoretically ejected into the soma from the recording electrode by rectangular current pulses (1.0-1.3 nA for $500 \mathrm{~ms}$ at $1 \mathrm{~Hz}$ ) for periods up to $15 \mathrm{~min}$ for A-fiber neurons and $8 \mathrm{~min}$ for $\mathrm{C}$-fiber neurons. Negative currents were used for dye injection of Lucifer yellow and cascade blue, and positive currents were used for ethidium bromide ejection. Usually five neurons per DRG were dye injected, using Lucifer yellow for one neuron at each end and one in the middle of the DRG and ethidium bromide for two neurons, one proximal and one distal to the middle Lucifer yellow injection site. Sometimes, a neuron lateral to a Lucifer yellow injection site was injected with cascade blue.

Precautions necessary to avoid the problems and pitfalls associated 
with identification of dye-injected cells (Lawson et al., 1997) were taken. Additionally, after dye injection, the receptive field properties and CV were checked to ensure that the electrode tip was still in the same neuron. Any doubt about the reliability of identity of dye-injected neurons, including weak fluorescent dye labeling, inappropriate position in the DRG, or more than one neuron labeled where one was expected (indicating likely dye leakage) led to rejection of that neuron.

Tissue processing. At the end of the experiment, the rat was given additional anesthetic and perfused with normal saline followed by Zamboni's fixative. DRGs were postfixed for $1 \mathrm{~h}$, left overnight in $30 \%$ sucrose buffer at $4^{\circ} \mathrm{C}$, and serial $7 \mu \mathrm{m}$ cryostat sections were cut and stored at $-20^{\circ} \mathrm{C}$ before immunostaining. After block of endogenous peroxidase and biotin-like activity with $2 \% \mathrm{H}_{2} \mathrm{O}_{2}$ and an avidin-biotin kit (Vector Laboratories, Peterborough, UK), respectively, ABC immunocytochemistry was used to demonstrate trkA-like immunoreactivity or immunoreactivity for one of two TTX-resistant $\mathrm{Na}^{+}$channel $\alpha$-subunits, Nav1.8like immunoreactivity (Djouhri et al., 2003b) and Nav1.9-like immunoreactivity (Fang et al., 2002), as described previously. Only one of these primary antibodies was used per section, but different ones were often used on different sections of the same dye-injected neuron. Sections were incubated with a primary rabbit polyclonal antibody for $48 \mathrm{~h}$ at $4^{\circ} \mathrm{C}$. These were anti-trkA at 1:7500 (a gift from L. F. Reichardt, University of California, San Francisco, San Francisco, CA), anti-Nav1.8 $\alpha$-subunit (SNS11) at $1.7 \times 10^{-3} \mu \mathrm{g} / \mathrm{ml}$, and anti-Nav1.9 $\alpha$-subunit at $1.7 \times 10^{-3} \mu \mathrm{g} / \mathrm{ml}$. Characterization of anti-trkA (Clary and Reichardt, 1994), anti-Nav1.8 (Djouhri et al., 2003b), and anti-Nav1.9 (Fjell et al., 2000) antibodies have been described previously. Sections were incubated for $30 \mathrm{~min}$ at room temperature with biotinylated secondary antibody (goat anti-rabbit Ig; 1:200; Vector Laboratories). Omission of primary antibody resulted in no staining.

Image analysis. The semiquantitative methods used to measure immunocytochemical intensities for Nav1.8 (Djouhri et al., 2003b) and Nav1.9 (Fang et al., 2002) were described previously and are described below for trkA. The methods used to measure trkA immunocytochemical staining intensity in non-dye-injected and single dye-injected DRG neurons were as follows. To examine the relationship between immunocytochemical intensity for trkA and neuronal size (cross-sectional area) of non-dyeinjected DRG neurons (for comparison with that for dye-injected neurons), all neuronal profiles containing a nucleus in all sections at $140 \mu \mathrm{m}$ intervals from a single L5 DRG from each of three experimental rats were analyzed with image analysis. Images were captured $(40 \times$ objective, bright-field optics) with a digital camera (Hamamatsu; Digital Pixel, Brighton, UK) and montaged to reproduce the entire section. The neuronal cross-sectional area (including the nucleus) and mean pixel density of immunostaining in the cytoplasm (excluding the nucleus) were determined using Digital Pixel software. For all antibodies, a low level of background staining enabled even negative neurons and their nuclei to be clearly visualized. For each DRG, the 100 and $0 \%$ values were calculated by averaging the cytoplasmic density of immunostaining from the five most strongly $(100 \% ; b)$ and the five least strongly $(0 \% ; a)$ stained neuronal profiles, and for each neuron, cytoplasmic density $(c)$ was used to calculate the relative intensity (percentage of maximum) as follows: immunostaining relative intensity (percentage $)=100 \times(c-a) /(b-a)$.

For single dye-injected neurons, immunostaining was subjectively scored from 0 (negative) or 1-5 (positive, 5 being the score of the most strongly stained profile in the section). In addition, relative intensity (cytoplasmic) of each dye-injected neuron was similarly calculated as a percentage of maximum neuronal cytoplasmic intensity (Fang et al., 2002) by comparing its intensity $(c)$ with the intensities of three clearly negative $(0 \% ; a)$ and of the three most strongly labeled neurones $(100 \%$; $b)$ in the same section, using the same equation as above.

The terms trkA, Nav1.8, or Nav1.9 intensity or immuno-intensity from this point on mean relative intensity of immunostaining for trkA, Nav1.8, or Nav1.9, respectively.

The methods used to determine the borderline of relative intensity between neurons that were positive and negative for trkA staining were described previously for Nav1.8 (Djouhri et al., 2003b) and Nav1.9 staining (Fang et al., 2002). As for these $\mathrm{Na}^{+}$channels, calculated trkA intensities were highly positively correlated with subjective scores (linear re- gression analysis; $r^{2}=0.97 ; p<0.0001$ ), and neurons with intensity $\geq 20 \%$ were consistently judged as positive (subjective score, $\geq 1$ ), whereas those with intensity $<20 \%$ were consistently scored as appearing negative (subjective score, $<1$ ). Thus, for trkA (as for the $\mathrm{Na}^{+}$channels), the borderline between negative (trkA-) and positive (trkA+) neurons was defined as $20 \%$ intensity. The term negative is used for consistency with the literature and for simplicity of communication, with the caveat that even below $20 \%$ intensity, percentage values may indicate real (low) levels of immunoreactivity. Based on the distributions of data (see below), neurons were classed as strongly ( $\geq 40 \%$ relative intensity) or weakly $(20-40 \%)$ positive.

Cell size. The largest cross-sectional area of all the sections of each dye-injected neuron was taken as a measure of its size; if the largest section was not available, that neuron was excluded from size analyses. As defined previously in relation to the shape of the size distributions of neurons (Fang et al., 2002), those within the small cell peak are called small (cross-sectional area up to $400 \mu \mathrm{m}^{2}$; diameter, $23 \mu \mathrm{m}$ ), those above $800 \mu \mathrm{m}^{2}$ area (32 $\mu \mathrm{m}$ diameter) are called large, because this includes only the extreme right-hand end of the large light cell distribution (Lawson et al., 1984), and those with areas of $400-800 \mu \mathrm{m}^{2}(23-32$ $\mu \mathrm{m}$ diameter) were classified as medium-sized.

Action potential variables and acceptance criteria. Analyzed somatic AP variables included AP: duration at base, rise time, fall time, overshoot and height, plus afterhyperpolarization duration to $80 \%$ recovery [Djouhri et al. (1998), their Fig. 1]. These variables were measured only in neurons with resting membrane potentials that were equal to, or more negative than, $-40 \mathrm{mV}$ with one exception: $-39 \mathrm{mV}$ in one $\mathrm{C}$ nociceptor. Apart from AP size (overshoot and height), all other AP variables were measured only in neurons with a positive AP overshoot. AP overshoot and AP height were measured in neurons with an AP height of at least $35 \mathrm{mV}$ and an AP peak that reached to at least $-20 \mathrm{mV}$, because it has been shown that some DRG neurons (mainly fast conducting LTMs) do not have overshooting APs (Djouhri and Lawson, 2001). For CV only, all neurons were included regardless of AP size and resting membrane potential.

$\mathrm{Na}^{+}$channel data. To increase the number of data points, some previously published Nav1.8 and Nav1.9 data (Fang et al., 2002; Djouhri et al., 2003b) were added to the novel data (for $n$ values, see Results). These combined data were analyzed, enabling direct comparisons between the correlations for Nav1.8, Nav1.9, and trkA immuno-intensities with electrophysiological properties.

Statistics. Linear regression analysis (see Figs. 2, 3, 4) and nonparametric Mann-Whitney $U$ tests and Kruskal-Wallis tests on data shown in Figures 1 and 2 were performed with Prism 3 (GraphPad Software, San Diego, CA).

Possible sources of error or sampling bias. Because intracellular penetrations and recording stability are easier in large neurons, and because $\mathrm{A} \alpha / \beta$ LTMs were rejected in some experiments, and because unresponsive neurons are harder to categorize, the proportions of different types of dye-labeled neurons (e.g., A-fiber neurons compared with C-fiber neurons, or C-fiber nociceptive compared with C-fiber unresponsive) do not necessarily represent their numerical distribution within the DRG. However, the percentages of immunopositive neurons within a particular group (e.g., A $\delta$ nociceptors, $\mathrm{A} \delta \mathrm{D}$ hair units, $\mathrm{A} \alpha / \beta$ nociceptors) are considered representative for that group.

\section{Results}

Comparison of the relationship between cell size and trkA intensity for neurons that were not dye injected (Fig. $1 A$ ) and neurons that were dye injected (Fig. $1 B$ ) shows a similar distribution pattern in both cases, indicating that the trkA immunoreactivity was not discernibly altered by recording and dye injection.

Overall, in non-dye-injected neurons (Fig. 1A), 75\% (830 of 1098 ) of small, $58 \%$ (205 of 353) of medium-sized, and $43 \%$ (40 of 94) of large neurons were trkA positive; overall, 70\% (1075 of 1545 ) of all neurons were classed as trkA + , including 37\% (573 of 1545 ) that were strongly positive (intensity, $\geq 40 \%)$. Most (77\%; 830 of 1075) of the trkA+ neurons were small (Fig. 1A). The small-medium size of somata with strong trkA staining is consis- 
A Non Dye-injected

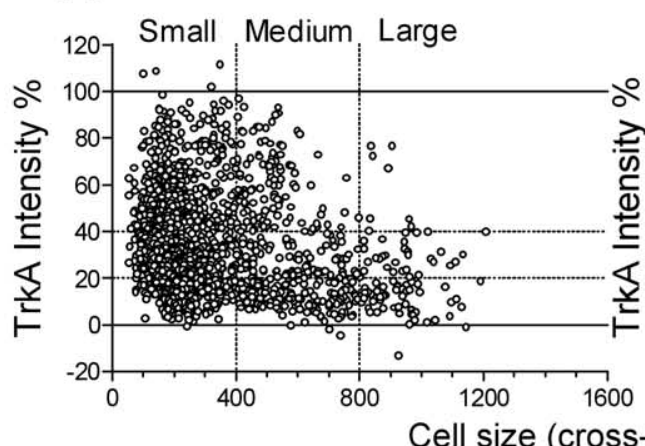

B Dye-injected

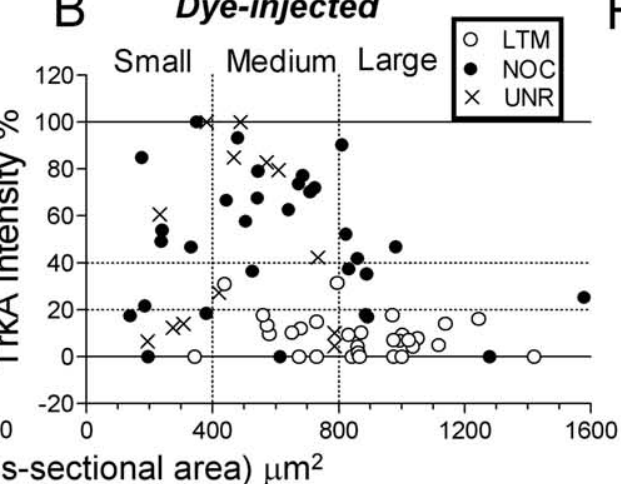

$\mathrm{F}$
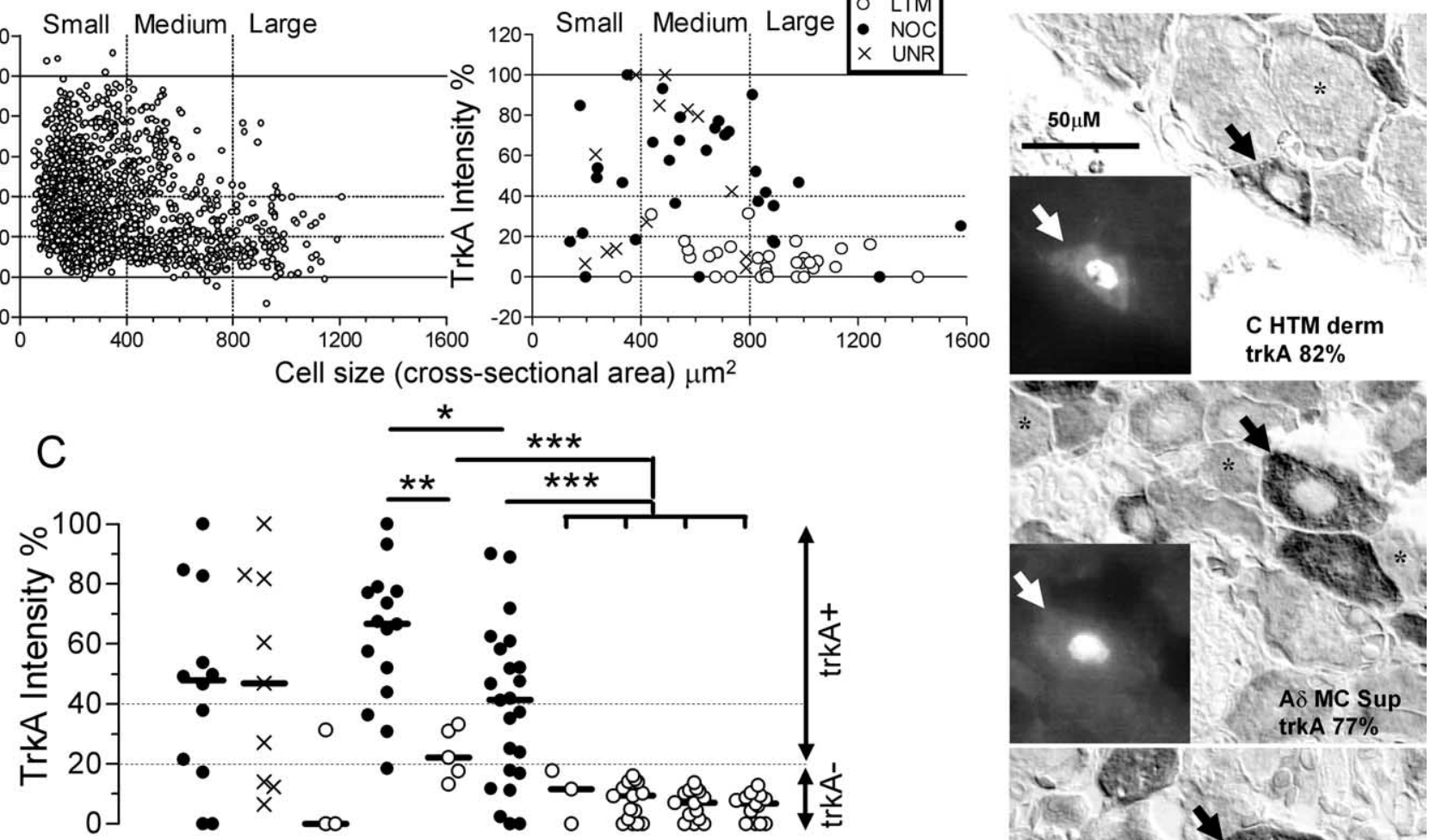

NOC UNR LTM NOC LTM NOC SA F/G RA MS
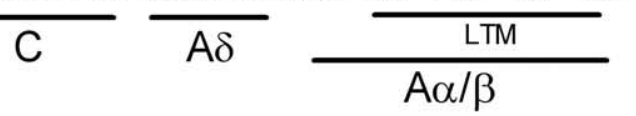

C-fiber units

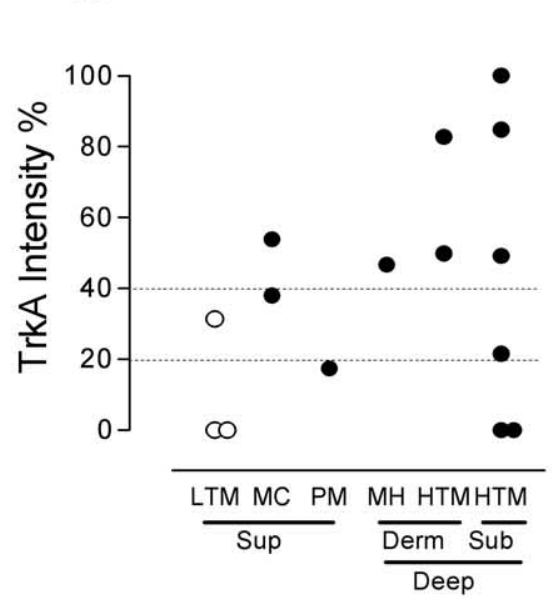

E A $\alpha / \beta$ HTM units

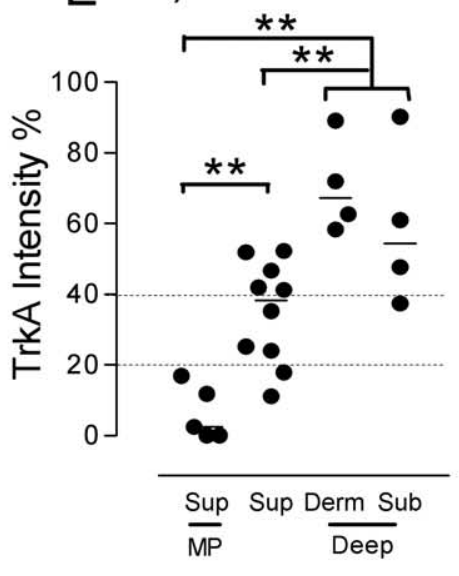

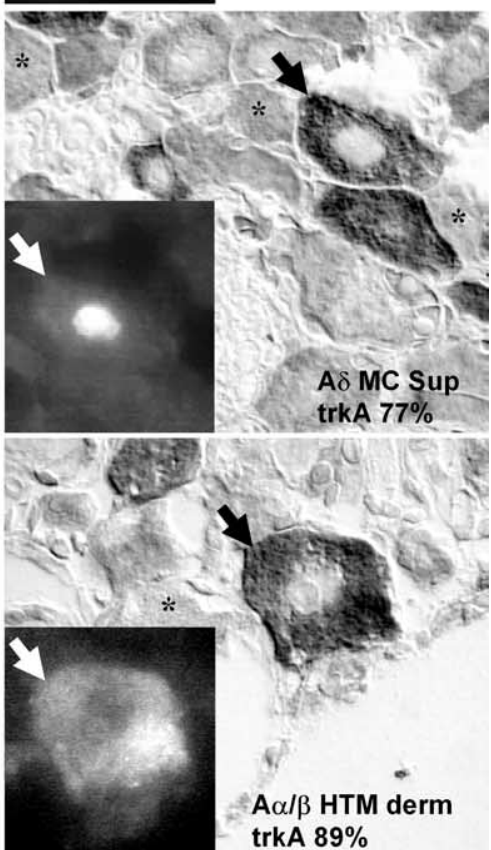

trkA $89 \%$

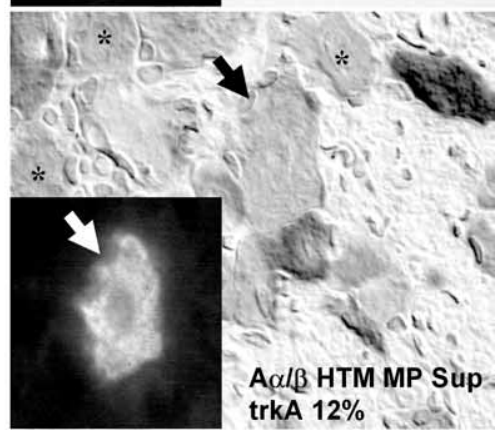

Figure 1. $\quad \boldsymbol{A}, \boldsymbol{B}$, Sizes of all non-dye-injected neuronal profiles with nuclei in sections of one $L 5 \mathrm{DRG}$ from each of three rats $(\boldsymbol{A})$ compared with those of identified dye-injected neurons $(\boldsymbol{B})$. Vertical dotted lines indicate boundaries between small, medium, and large neurons. Horizontal dotted lines indicate borderlines between negative and positive neurons and between weakly positive $(20-40 \%)$ and strongly positive $(\geq 40 \%)$ neurons. $C$, trkA intensities of physiologically identified DRG neurons; a Kruskal-Wallis test comparing medians of the three groups of nociceptors shows a significant difference between $A \delta$ and $A \alpha / \beta$ neurons and no differences between the four groups of $A \alpha / \beta$ LTMs; Mann-Whitney $U$ tests show significant differences between $A \delta$ nociceptors and A $\delta$ LTM neurons, between $A \alpha / \beta$ nociceptors and LTMs, and between $A \delta$ and all $A \alpha / \beta$ LTMs. CLTM neurons are excluded, because $n=3$. D, trkA intensity in CLTMs and populations of C nociceptive neurons. $E$, Comparisons of trkA intensities of $A \alpha / \beta$-fiber HTM subgroups. Moderate pressure (MP) units had significantly lower trkA intensities than other HTMs with superficial or deeper (dermal and subcutaneous together) receptive fields, and HTMs with superficial receptive fields had significantly lower intensities than units with deep receptive fields (Mann-Whitney tests). $\boldsymbol{F}$, Photomicrographs show fluorescent images of representative dye-injected neurons in insets to left: dyes were Lucifer yellow, cascade blue, and for the two lowest cells ethidium bromide; note the typically nuclear fluorescence with cascade blue and Lucifer yellow. The same neurons stained for trkA, under interference contrast optics, are indicated by arrows (right). Asterisks indicate examples of trkA neurons. The top three injected neurons are strongly trk + , and the last is a trkA-MP unit. The scale bar ( $50 \mu \mathrm{m}$; top left image) applies to all photomicrographs, including insets. For $\boldsymbol{C}$ and $\boldsymbol{E}$, $p<<$ 0.05 , ${ }^{* *} p<0.01,{ }^{* * *} p<0.001$. NOC, Nociceptive; UNR, C-fiber unresponsive; SA, slowly adapting; F/G, field or guard hair; RA, rapidly adapting; MS, muscle spindle; MC, mechano-cold; PM, polymodal; MH, mechano-heat. Depth in tissues: Sup, superficial; Derm, dermal; Sub, subcutaneous. 
tent with previously published data (Averill et al., 1995; Bennett et al., 1996). The similarity in previously published percentages of positive neurons (35-40\%) (Averill et al., 1995; Kashiba et al., $1995)$ to our strongly stained neurons (37\%) suggests that these investigators used criteria for defining trkA + staining that are close to $40 \%$ intensity (strongly positive in our study), a level that we find is selective for nociceptive somatic afferent neurons (see below). Thus, neurons in the present study with weak but positive trkA staining may not be classed as positive by other groups. Our finding that some A-fiber neurons are trkA+ (Fig. 1C) is consistent with trkA expression in some medium-large sized DRG neurons (Fig. $1 B$ ) and with observations (Averill et al., 1995; Molliver et al., 1995) that some trkA+ neurons are neurofilament rich, indicative of having myelinated fibers (Lawson and Waddell, 1991).

\section{trkA intensity and sensory receptive properties}

In total, 122 neurons were successfully dye injected with fluorescent dye, found in the appropriate location, and stained for trkA. These included 62 neurons labeled with Lucifer yellow dye, 48 with ethidium bromide dye, and 12 with cascade blue dye. These were classified as 50 nociceptive (12 C, $2 \mathrm{C} / \mathrm{A} \delta, 13 \mathrm{~A} \delta, 23 \mathrm{~A} \alpha / \beta)$, $53 \mathrm{LTM}(3 \mathrm{C}, 5 \mathrm{~A} \delta, 45 \mathrm{~A} \alpha / \beta)$, and 19 unresponsive neurons (9 C, $1 \mathrm{C} / \mathrm{A} \delta, 2 \mathrm{~A} \delta, 7 \mathrm{~A} \alpha / \beta)$.

\section{Nociceptive neurons}

Most C-, $\mathrm{A} \delta$-, and $\mathrm{A} \alpha / \beta$-nociceptive and $\mathrm{C}$-unresponsive neurons $(75,93,70$, and $68 \%$, respectively) were trkA+ (intensity, $\geq 20 \%$ ). Overall, $61 \%$ of nociceptors were strongly trkA + , and an additional $16 \%$ were weakly trkA + , making $78 \%$ of all nociceptive neurons trkA + in total. Higher percentages of $A \delta$ nociceptors $(80 \%)$ than of $\mathrm{C}(58 \%)$ and $\mathrm{A} \alpha / \beta(52 \%)$ nociceptors and C-unresponsive (56\%) neurons were strongly trkA+ (i.e., intensity, $\geq 40 \%$ ). Surprisingly, percentages of nociceptive neurons that were trkA+ or strongly trkA+ were as high for $\mathrm{A} \alpha / \beta$ as for $\mathrm{C}$ nociceptors. The only neurons that were strongly trkA+ (intensity, $\geq 40 \%$ ) were nociceptor type (Fig. 1C, nociceptive or $\mathrm{C}$-unresponsive). Two $\mathrm{C} / \mathrm{A} \delta$ nociceptors included in the $\mathrm{A} \delta$ group had trkA intensities of 65 and 19\%. Finally, some C- (25\%), A $\delta$ (7\%), and $A \alpha / \beta-(30 \%)$ nociceptive neurons were not trkA+.

trkA median intensities tended to be higher for A $\delta$ nociceptors (median intensity 67\%) than for C nociceptors (48\%), C unresponsive $(47 \%)$, and $A \alpha / \beta$-fiber nociceptors (41\%) (Fig. $1 C)$; this difference was significant between $\mathrm{A} \delta$ - and $\mathrm{A} \alpha / \beta$-fiber nociceptors $(p<0.05)$. Examples of trkA immunoreactivity in nociceptors with $\mathrm{C}, \mathrm{A} \delta$, and $\mathrm{A} \alpha / \beta$ fibers are shown in Figure $1 F$.

\section{C nociceptors}

These ranged in trkA intensity from 0 to $100 \%$ (Fig. 1C,D). Examination of subdivisions of $\mathrm{C}$ nociceptors (Fig. 1D) showed that: (1) most (five of eight) C HTM units were strongly trkA+, an additional unit was weakly trkA+; (2) two of two C mechanocold units were trkA + ; both fired spontaneously at room temperature; (3) one of two C heat responsive (polymodal/mechanoheat) unit was trkA+, and the remaining unit was trkA- but with an intensity only just below 20\%; (4) of the trkA + C nociceptors with superficial receptive fields that were tested with noxious heat, zero of two responded to heat; (5) all three $\mathrm{C}$ nociceptors with trkA intensities $>80 \%$ projected to deep (dermal or subcutaneous) tissues, although two other $\mathrm{C}$ nociceptors projecting to subcutaneous tissues were trkA-.
A $\delta$ nociceptors

Most (>90\%) A $\delta$ nociceptors were trkA +, and most (80\%) were strongly trkA+ (intensity, $\geq 40 \%$ ) (Fig. 1C). Two A $\delta$ mechanocold nociceptors were strongly trkA+ (intensity, 77 and 79\%). There was no significant difference in median intensity between A $\delta$ HTM units with receptive fields in superficial (median, 59\%; $n=5$ ) and deep tissues (dermal and subcutaneous; median, 67\%; $n=8$; Mann-Whitney $U$ test; data not shown).

\section{A $\alpha / \beta$ nociceptors}

These were all classed as HTM units ( $n=16,7$ for glabrous skin and hairy skin, respectively) and were subdivided as follows: moderate pressure units with superficial receptive fields $(n=5$, $0)$ and other HTM units with superficial $(n=5,5)$, dermal $(n=$ $2,2)$, and subcutaneous $(n=4,0)$ receptive fields. Comparisons of median trkA intensities were made with Mann-Whitney $U$ tests for glabrous and hairy skin units combined. trkA intensity was not significantly different between units with dermal (54\%) and those with subcutaneous (67\%) receptive fields, and these were pooled as deep units for statistical analysis (Fig. 1E). In contrast, moderate pressure units (all trkA-) (Fig. $1 F)$ had a significantly lower median intensity $(2.5 \%)$ than other $A \alpha / \beta$ HTM units, both HTM units with superficial (median, 38\%; $p<$ 0.01 ) and those with deep receptive fields (median, $62 \% ; p<$ 0.01 ). Furthermore, even if moderate pressure units were excluded, HTMs with superficial receptive fields were less intensely labeled for trkA than those with deep receptive fields $(p<0.01)$ (Fig. $1 E)$. These differences and levels of significance $(p<0.01)$ were also found for glabrous units alone (data not shown), but there were too few units with receptive fields in hairy skin for statistical analysis on their own.

\section{Unresponsive units}

The C-fiber unresponsive units had trkA intensities as high as the C-fiber nociceptors (Fig. 1C). This high trkA level is therefore additional evidence of a nociceptor-type phenotype, supporting previous evidence that such units express phenotypic properties similar to those of nociceptors and consistent with the view that at some of these may be silent nociceptors with very high sensory thresholds (Djouhri et al., 1998, 2003b). In addition, three A $\delta$ unresponsive units had strong trkA intensities (80-100\%), suggesting that these also have properties akin to nociceptors, whereas only one of seven $A \alpha / \beta$-unresponsive units was trkA+. The tendency of $A \alpha / \beta$-unresponsive units to be trkA- is presumably because most (80\%) A $\alpha / \beta$ units are LTMs (our unpublished data); there is therefore a higher chance of $A \alpha / \beta$-unresponsive units being LTMs with inaccessible receptive fields than in C and $\mathrm{A} \delta$ groups in which the proportion of LTMs is much lower.

\section{LTM neurons}

In contrast to nociceptors, most LTMs were $\operatorname{trk} A-($ all $A \alpha / \beta$, two of five $\mathrm{A} \delta$, and two of three C LTMs) or only weakly trkA+ (one of three $\mathrm{C}$ and three of five A $\delta$ LTMs) (Fig. $1 C$ ). The few C LTMs (too few for statistic comparisons) tended to have much lower trkA intensities than $\mathrm{C}$ nociceptors or unresponsive units (Fig. $1 C)$. Similarly, LTMs had lower intensities than nociceptors in both the $\mathrm{A} \delta$ and $\mathrm{A} \alpha / \beta \mathrm{CV}$ ranges (Mann-Whitney tests; $p<0.01$ and 0.001 , respectively). A $\delta$ LTM D hair units had a significantly higher (22\%) median trkA intensity than that for all A $\alpha / \beta$ LTMs grouped together $(7 \% ; n=45 ; p<0.001)$, but all $A \alpha / \beta$ cutaneous LTMs (8\%) and A $\alpha / \beta$ muscle spindle LTMs (7.8\%) had similar low values (Fig. $1 C$ ). 

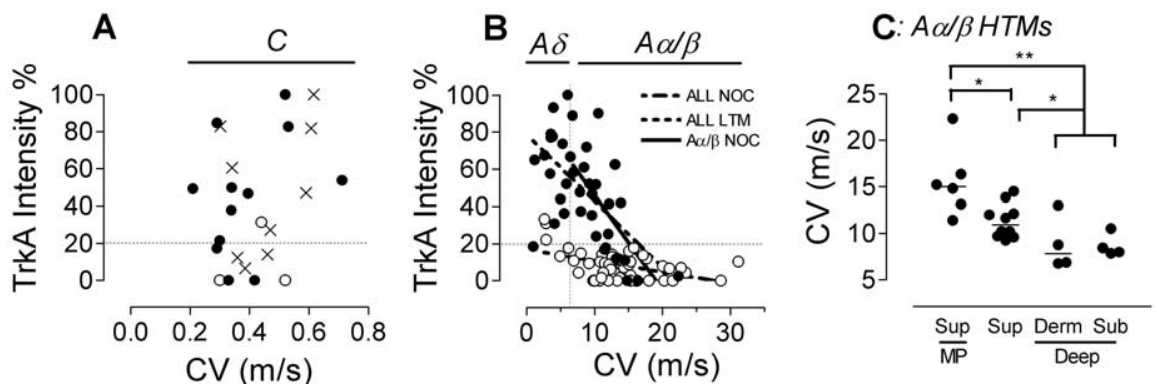

ables (data not shown); in all nociceptive units, it was correlated with none of them. In all LTM units, it was weakly positively correlated only with AP rise time.

When neurons were divided into different CV groups, surprisingly there were no correlations of trkA intensity with AP variables for all $\mathrm{C}$ or all $\mathrm{A} \delta$ neurons, or for nociceptors or LTMs separately in either of these CV groups, with the exception of a weakly positive correlation with AP rise time in all $\mathrm{C}$ neurons $\left(n=12 ; r^{2}=0.39\right.$; $p<0.05$; data not shown). The lack of correlation of trkA intensity with AP duration for both $\mathrm{C}$ and $\mathrm{A} \delta$ neurons can be seen in Figure $3 A$.

In contrast, for $A \alpha / \beta$ neurons, there were many significant positive correlations with trkA intensity including: all variables for all $\mathrm{A} \alpha / \beta$ neurons, all vari-

trkA intensity and dorsal root CVs

Given the known trkA expression in small DRG neurons, the negative correlation between trkA intensity and CV for all neurons $\left(p<0.0001 ; r^{2}=0.26\right.$; data not shown) was expected. Furthermore, the lack of correlation within A $\alpha / \beta$ LTMs was to be expected, because they were all trkA- (Fig. $2 B$ ). However, a correlation for all A-fiber LTMs $\left(p<0.001 ; r^{2}=0.22\right)$ (Fig. $\left.2 B\right)$ appears to result from the higher trkA in A $\delta$ than in A $\alpha / \beta$ LTM units.

In contrast to the lack of correlation in C-fiber neurons regardless of sensory properties (Fig. $2 A$ ), there were clear correlations between $\mathrm{CV}$ and trkA intensity (Fig. $2 B$ ) for all A-fiber neurons $\left(p<0.0001 ; r^{2}=0.35\right.$; line not shown $)$, for all $\mathrm{A} \alpha / \beta$ neurons $\left(p<0.0005 ; r^{2}=0.21\right.$; line not shown $)$, for A-fiber nociceptors $\left(p<0.0001 ; r^{2}=0.37\right)$, and for $A \alpha / \beta$ nociceptors $\left(p<0.0005 ; r^{2}=0.46\right)$ (Fig. 2 B). The clearest correlation was for $\mathrm{A} \alpha / \beta$ nociceptors, and this appears to be responsible for correlations seen within the entire population of A-fiber nociceptors and for all $A \alpha / \beta$ neurons. Furthermore, the lower relative intensity of trkA in $\mathrm{A} \alpha / \beta$ than $\mathrm{A} \delta$ nociceptors (Fig. $1 C$ ) results from the lower intensity of trkA in the more rapidly conducting $A \alpha / \beta$ units (Fig. $2 B$ ).

To determine whether there were differences in CV in the subgroups of $A \alpha / \beta$ nociceptors that may be related to the differences in trkA intensity in Figure $1 E$, we plotted CVs for each of these subgroups (Fig. 2C). The results were consistent with a possible causal relationship between expression of trkA and $\mathrm{CV}$, with greater trkA (Fig. $1 E$ ) and slower CVs (Fig. 2C) in deeper $\mathrm{A} \alpha / \beta$ nociceptors, with lower trkA and faster CVs in superficially projecting neurons, and also with even lower trkA and even faster CVs in the moderate pressure units compared with others that projected superficially (compare Figs. 1 E, 2C).

\section{trkA intensity and AP configuration}

We examined whether trkA intensity was correlated with any of the following: somatic AP duration at base, AP rise time, AP fall time, AP overshoot, AP height, and AP afterhyperpolarization duration to $80 \%$ recovery. Linear correlations for each of these against trkA intensity were examined for: (1) all neurons (excluding A-fiber unresponsive neurons), all nociceptors, and all LTMs; (2) for all $\mathrm{C}$, all $\mathrm{A} \delta$, and all $\mathrm{A} \alpha / \beta$ neurons; (3) for nociceptors separately for each CV group; and (4) for A $\alpha / \beta$ LTMs (too few C and $\mathrm{A} \delta$ LTMs met the criteria for analysis). In all neurons, trkA intensity was weakly positively correlated with all the above vari- ables except $\mathrm{AP}$ overshoot for $\mathrm{A} \alpha / \beta$ nociceptors, and only AP rise time for $\mathrm{A} \alpha / \beta$ LTMs. This last correlation is interesting, because all A $\alpha / \beta$ LTMs were trkA-, and it may indicate that even below $20 \%$ intensity, low levels of functional trkA may be present. These correlations are shown in Table 1. To illustrate these correlations, the relationships between trkA intensity and AP duration at base and AP height are shown in Figure 3. Figure $3 A$ shows that for all $\mathrm{A} \alpha / \beta$ (but not $\mathrm{C}$ and $\mathrm{A} \delta$ ) neurons, trkA intensity is clearly correlated with AP duration. Figure $3, B$ and $C$, shows that within the $\mathrm{A} \alpha / \beta$ group, there was a significant correlation for nociceptors, but not LTMs, between trkA intensity and both AP duration at base and AP height.

\section{TTX-resistant $\mathrm{Na}^{+}$channels and AP configuration}

A number of studies (Black et al. 1997; Dib-Hajj et al., 1998a) indicate that NGF upregulates expression of the $\mathrm{Na}^{+}$channel Nav1.8 within DRG neurons. This raises the possibility that trkA may be linked to electrophysiological properties via its regulation of NGF uptake and thus Nav1.8 expression. We therefore examined correlations of both Nav1.8 and, for comparison, Nav1.9 expression with electrophysiological properties to compare them with those for trkA described above. Because there were too few A-fiber nociceptors in previously published studies (Fang et al., 2002; Djouhri et al., 2003b) for separate analysis of A $\delta$ and $A \alpha / \beta$ nociceptors, more data were required for this comparison. We therefore performed additional studies of Nav1.8 and Nav1.9 expression in nociceptors and also included the units in those previous studies. The final numbers of nociceptors in each CV group that meet the electrophysiological criteria for analysis of most AP variables (AP overshoot and membrane potential of at least -40 $\mathrm{mV}$; see Materials and Methods) are given below with, in parentheses, the percentage of each total that was contributed by units in the previous study. Note that for AP height, numbers in some cases were higher (see Materials and Methods). For Nav1.8, numbers of nociceptive-type units were: $\mathrm{A} \alpha / \beta, n=17$ (41\%); $\mathrm{A} \delta, n=$ $13(23 \%)$; and C, $n=11(81 \%)$ [percentages relate to units from Djouhri et al. (2003b)]. For Nav1.9, units were: $\mathrm{A} \alpha / \beta, n=14$ $(42 \%) ; \mathrm{A} \delta, n=13(30 \%)$; and C, $n=10(70 \%)$ [percentages relate to units from Fang et al. (2002)]. In all groups, the numbers of A-fiber nociceptors examined in the present study for these $\mathrm{Na}^{+}$channels were thus doubled or tripled compared with the previously published data (Fang et al., 2002; Djouhri et al., 2003b). For both Nav1.8 and Nav1.9, smaller numbers (up to 
$30 \%)$ of LTMs were also added in the present study. The pooled data were analyzed and linear regression analyses performed exactly as described for the trkA data.

Nav1.8 expression showed correlations with electrophysiological properties that were remarkably similar to those for trkA in the following respects. (1) There was no linear correlation between Nav1.8 intensity and any AP variables in subgroups of $\mathrm{C}$ and $\mathrm{A} \delta$ units (Fig. 3, AP duration). (2) In all $\mathrm{A} \alpha / \beta$ neurons, Nav1.8 intensity showed a significant linear correlation with all AP variables exactly as seen for trkA (Table 1), with the exception of AP height but even for trkA this correlation with AP height was weak $\left(r^{2}=0.09\right)$ (Fig. 3 , Table 1). (3) In A $\alpha / \beta$ nociceptors, as for trkA, Nav1.8 was correlated with AP afterhyperpolarization duration to $80 \%$ recovery, and AP height with similar $r^{2}$ values to those for trkA (Table 1). (4) Again as for trkA, there was a significant correlation with similar $r^{2}$ values between Nav1.8 intensity and AP rise time for $A \alpha / \beta$ LTMs, despite the fact that a few $A \alpha / \beta$ LTMs were Nav1.8 positive, but none were positive for trkA. Furthermore, in $A \alpha / \beta$ nociceptors, $X Y$ plots of Nav1.8 against AP duration, $\mathrm{AP}$ rise time, and fall time variables, although they were not significantly correlated, tended to show similar patterns to those for trkA (Fig. 3, AP duration). The above observations demonstrate similar relationships of electrophysiological properties with both Nav1.8 and trkA intensities in $\mathrm{A} \alpha / \beta$ nociceptors, suggesting a functional link between the two. Interestingly, similar patterns for A $\alpha / \beta$ LTMs, with correlations between AP rise time and both trkA and Nav1.8, may support the view that even low levels (below 20\% intensity) of trkA may be enough to influence Nav1.8 expression (see below).

In contrast to Nav1.8, relationships of Nav1.9 with electrophysiological properties did not resemble those for trkA (Fig. 3). There was no significant correlation between Nav1.9 intensity and $\mathrm{AP}$ variables in $\mathrm{C}, \mathrm{A} \delta$, or $\mathrm{A} \alpha / \beta$ neurons (Fig. $3 A$, AP duration), with the exception of AP rise time in all C-fiber nociceptortype neurons $\left(n=10 ; p<0.01 ; r^{2}=0.70\right.$; data not shown $)$ and in all C-fiber neurons $\left(n=11 ; p=0.0004 ; r^{2}=0.77\right.$; data not shown) and AP overshoot in all A $\alpha / \beta$ neurons (Table 1). Thus, the relationships between immunoreactivity for trkA and AP variables resembled much more closely the relationships for Nav1.8 than for Nav1.9.

Because CV is known to be related to $\mathrm{Na}^{+}$channel expression, similar relationships between $\mathrm{CV}$ and both trkA and Nav1.8, but not Nav1.9, intensity also support a possible functional connection between trkA and Nav1.8. These patterns include (1) correlations for all $\mathrm{A} \alpha / \beta$ neurons between $\mathrm{CV}$ and both trkA (this paper) and Nav1.8 ( $p=0.0002 ; n=65$; this paper $)$ that are not seen for Nav1.9 (Fang et al., 2002) plus (2) a lack of correlation between CV and both trkA (this paper) and Nav1.8 intensities (Djouhri et al., 2003b) in C-fiber neurons, although there is a clear correlation between CV and Nav1.9 intensity in these neurons (Fang et al., 2002).

\section{Colocalization of trkA with TTX-resistant $\mathrm{Na}^{+}$channel subunits in DRG neurons}

To determine whether the expression levels of trkA and Nav1.8 were related in individual neurons, we compared the intensities of trkA and Nav1.8 ( $n=97$; excluding A-fiber unresponsive neurons) and, for comparison, also of trkA and Nav1.9 $(n=96$; excluding A-fiber unresponsive units) in different sections from the same identified neurons. Linear regression analysis was performed on all neurons, all $\mathrm{C}$, all $\mathrm{A} \delta$, and all $\mathrm{A} \alpha / \beta$ neurons, and on nociceptive neurons of each CV group (Fig. 4).

There was a correlation between trkA and Nav1.8 intensities for all neurons $\left(n=97 ; r^{2}=0.40 ; p<0.0001\right.$; data not shown) and for all nociceptor-type neurons $\left(n=51 ; r^{2}=0.14 ; p<0.01\right.$; data not shown). Of the other groups tested, the only significant 
Table 1. A $\alpha / \beta$ neurons: trkA, TTX-resistant $\mathrm{Na}^{+}$channel intensities versus AP variables

\begin{tabular}{|c|c|c|c|c|c|c|c|c|c|c|c|c|c|c|c|c|c|c|}
\hline & \multicolumn{3}{|c|}{ AP duration } & \multicolumn{3}{|c|}{ Rise time } & \multicolumn{3}{|c|}{ Fall time } & \multicolumn{3}{|c|}{ AHP80 duration } & \multicolumn{3}{|c|}{ AP overshoot } & \multicolumn{3}{|c|}{ AP height } \\
\hline & $p$ & $r^{2}$ & $n$ & $p$ & $r^{2}$ & $n$ & $p$ & $r^{2}$ & $n$ & $p$ & $r^{2}$ & $n$ & $p$ & $r^{2}$ & $n$ & $p$ & $r^{2}$ & $n$ \\
\hline \multicolumn{19}{|c|}{ trkA versus } \\
\hline LTM & NS & & 25 & * & 0.2 & 25 & NS & & 25 & NS & & 25 & NS & & 36 & NS & & 36 \\
\hline NOC & * & 0.29 & 20 & * & 0.28 & 20 & * & 0.25 & 20 & * & 0.25 & 20 & NS & & 21 & * & 0.22 & 21 \\
\hline All & $* * * *$ & 0.49 & 45 & $* * * *$ & 0.51 & 45 & $* * * *$ & 0.41 & 45 & $* * *$ & 0.25 & 45 & $* * *$ & 0.19 & 57 & * & 0.09 & 57 \\
\hline \multicolumn{19}{|c|}{ Nav1.8 versus } \\
\hline LTM & NS & & 27 & * & 0.15 & 27 & NS & & 27 & NS & & 26 & NS & & 37 & NS & & 37 \\
\hline NOC & NS & & 17 & NS & & 17 & NS & & 17 & $*$ & 0.28 & 17 & $*$ & 0.22 & 19 & * & 0.23 & 19 \\
\hline All & $* * * *$ & 0.31 & 44 & $* * *$ & 0.30 & 44 & $* * *$ & 0.27 & 44 & $* *$ & 0.16 & 43 & $* *$ & 0.14 & 56 & NS & & 56 \\
\hline \multicolumn{19}{|c|}{ Nav1.9 versus } \\
\hline LTM & NS & & 23 & NS & & 23 & NS & & 23 & NS & & 23 & NS & & 29 & NS & & 29 \\
\hline NOC & NS & & 13 & NS & & 13 & NS & & 13 & $(*)$ & 0.28 & 13 & NS & & 16 & NS & & 16 \\
\hline All & $(*)$ & 0.09 & 36 & NS & & 36 & $(*)$ & 0.09 & 36 & NS & & 36 & * & 0.09 & 45 & NS & & 45 \\
\hline
\end{tabular}

Linear correlation analysis of trkA intensity and Nav1.8 or Nav1.9 intensity with AP duration at base, AP rise time, AP fall time, AP afterhyperpolarization duration to $80 \%$ recovery (AHP80 duration in the table), AP overshoot, and AP height in $A \alpha / \beta$ neurons was performed. Unresponsive neurons are excluded. All neurons had resting membrane potential equal to or more negative than $-40 \mathrm{mV}$. All neurons analyzed for AP duration, rise time, fall time, and AHP80 durations had overshooting APs. All neurons analyzed for AP overshoot and height had AP overshoot greater than or equal to $-20 \mathrm{mV}$ and height $\geq 35 \mathrm{mV}$. In each case where $p<0.1, r^{2}$ and $n$ values are given. NS, $p>0.05$; $(*) 0.05<p<0.1 ;$ ${ }^{*} p<0.05 ;{ }^{* *} p<0.01 ;{ }^{* * *} p<0.001 ;{ }^{* * * *} p<0.0001$. NOC, Nociceptive neurons. C - and A $\delta$-fiber neurons were excluded from this table, because their trkA, Nav1.8, and Nav1.9 intensities were not correlated with any of these variables except for positive correlations of trkA and Nav1.9 with AP rise time in all C-fiber neurons (see Results).
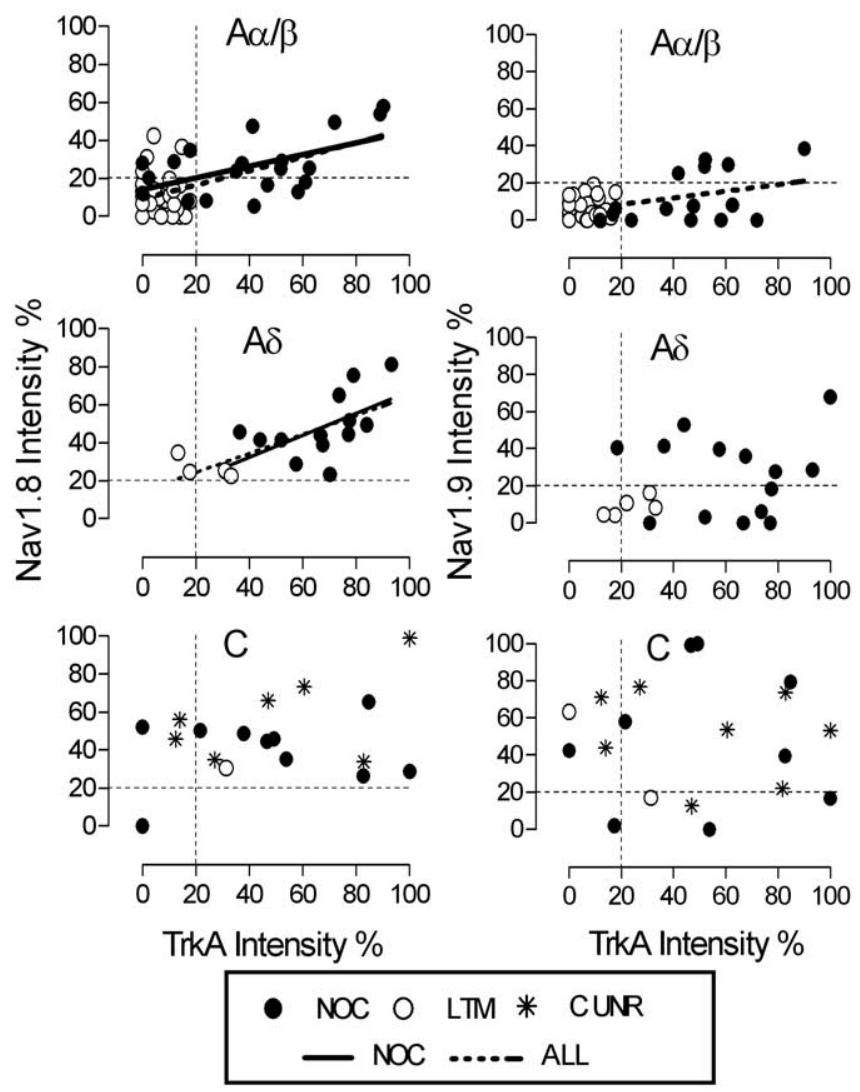

Figure 4. trkA intensity versus Nav1.8 (left) or Nav1.9 (right) intensity in different sections from the same identified neurons. A-fiber unresponsive neurons are excluded. Left, $A$ linear correlation between trkA intensity and Nav1.8 intensity exists in all $A \alpha / \beta$ units $(p<0.0001$; $\left.r^{2}=0.36\right) ; A \alpha / \beta$ nociceptors $\left(p<0.005 ; r^{2}=0.29\right)$; all A $\delta$ units $\left(p<0.005 ; r^{2}=0.48\right)$; A $\delta$ nociceptors $\left(p<0.005 ; r^{2}=0.38\right)$. No such correlation is in C-fiber units $(p>0.05)$. Right, There is a linear correlation between trkA intensity and Nav1.9 intensity only in all $A \alpha / \beta$ units $\left(p<0.005 ; r^{2}=0.17\right)$. The vertical and horizontal dotted lines from $y$-axis and from $x$-axis indicate the borderlines between positive and negative for trkA and for Nav1.8 or Nav1.9, respectively. NOC, Nociceptive; C UNR, C-fiber unresponsive. For $p, n$, and $r^{2}$ values, see Results.

correlations were for all A $\alpha / \beta$ neurons $\left(n=61 ; p<0.0001 ; r^{2}=\right.$ $0.36)$, for $\mathrm{A} \alpha / \beta$ nociceptors $\left(n=20 ; p<0.05 ; r^{2}=0.29\right)$, for all A $\delta$ units/neurons $\left(n=18 ; p<0.005 ; r^{2}=0.48\right)$, and for all $\mathrm{A} \delta$ nociceptors $\left(n=14 ; p<0.005 ; r^{2}=0.38\right)$ (Fig. 4). For trkA and
Nav1.9 intensities, there were fewer correlations, with lower $r^{2}$ values, than for Nav1.8; these correlations were only observed for all A $\alpha / \beta$ neurons together $\left(n=56 ; p<0.005 ; r^{2}=0.17\right)$ (Fig. 4$)$ and all neurons together $\left(n=96 ; p=0.0001 ; r^{2}=0.15\right)$ (data not shown).

\section{Discussion}

This is the first study to determine directly the sensory properties of somatic afferent DRG neurons that express trkA in normal adult rats. It demonstrates that intense trkA staining is confined exclusively to nociceptors and that trkA expression is higher in nociceptive than LTM DRG neurons in all CV ranges, although some slowly conducting LTMs are weakly trkA+. Additional novel findings include: (1) trkA intensity as intense in $\mathrm{A} \alpha / \beta$ nociceptors as in C and A $\delta$ nociceptors; (2) trkA intensity correlated negatively with $\mathrm{CV}$ and positively with $\mathrm{AP}$ duration in $\mathrm{A} \alpha / \beta$, but not $\mathrm{A} \delta$ and $\mathrm{C}$, nociceptors; (3) similar correlations of both trkA and Nav1.8 intensities with several electrophysiological properties in $\mathrm{A} \alpha / \beta$ nociceptors; and (4) direct correlations between intensities of trkA and Nav1.8 in A-, not C-, fiber nociceptors.

\section{trkA expression in nociceptive neurons}

Expression of trkA by nociceptors in all CV ranges is consistent with an influence of NGF on their physiological properties, as reported previously for A-fiber nociceptors (Ritter et al., 1991). Some C-fiber nociceptors are strongly trkA+, and others are trkA-. From immunocytochemical and electrophysiological studies, it seems likely that many of the latter should bind isolectin B4 (IB4) and that some or all of these are also nociceptive (Averill et al., 1995; Gerke and Plenderleith, 2001) (our unpublished data). These IB4-binding/trkA - small DRG neurons are dependent on GDNF (Zwick et al., 2002). The high trkA intensity in some $\mathrm{A} \alpha / \beta$ nociceptors (indicating a likely NGF dependence) was unexpected, mainly because little is known about these neurons (Lawson, 2002; Djouhri and Lawson, 2004).

\section{trkA expression in LTM neurons}

The weak positive labeling for trkA in some C LTMs and A $\delta$ D hair LTMs and the correlation with AP rise time in A $\alpha / \beta$ LTMs suggest a possible (perhaps weak) influence of NGF on these neurons. This may be consistent with the proposed dependence on postnatal NGF availability for the development of A $\delta$ cutane- 
ous afferent precursors into nociceptors or D hair units (Lewin et al., 1992).

\section{trkA expression and receptive field location}

Our findings that both the $\mathrm{C}$ and $\mathrm{A} \alpha / \beta$ nociceptors with the greatest trkA intensity tend to project to deep tissues, whereas those with lower trkA project more superficially, are consistent with previous findings in rat glabrous skin that more trkA+ neurons project to deep than to superficial (epidermal) tissues (Lu et al., 2001). Because expression of substance $P$ and calcitonin generelated peptide (CGRP) in DRG neurons is NGF dependent (Verge et al., 1995), the present findings are also consistent with the greater substance P and CGRP immunoreactivity in dermally than in more superficially projecting $\mathrm{C}$ nociceptors in guinea pig (Lawson et al., 1997, 2002). trkA expression in DRG neurons may be partially influenced by NGF availability in target tissues (Li et al., 2000). It is therefore interesting that the superficial/low trkA and deep/higher trkA relationships are similar for C- and A-fiber nociceptors.

The lower trkA intensities of $A \alpha / \beta$ nociceptors with faster CVs that tend to project to superficial (epidermal) rather than deeper tissues may be related to expression of a less extreme nociceptive phenotype, because this group includes moderate pressure units with mechanical nociceptive thresholds that are intermediate between those of other HTMs and LTMs.

\section{trkA expression, NGF, and electrophysiology of A $\alpha / \beta$ nociceptors}

The finding that $A \alpha / \beta$ (but not $\mathrm{A} \delta$ and $\mathrm{C}$ ) nociceptors with higher trkA expression have broader APs, greater AP heights, and slower CVs indicates that the extent of their nociceptive electrophysiological phenotype may be regulated mainly by NGF/trkA in these nociceptors. The extent to which their nociceptive phenotype might be altered by changes in the NGF/trkA pathway in disease states remains to be determined.

\section{Possible mechanisms underlying correlation between trkA and electrophysiology in $A \boldsymbol{\alpha} / \boldsymbol{\beta}$ nociceptors}

Mechanisms underlying the correlation of trkA intensity with CV can only be speculated on but presumably involve NGF mediated influence/s. For example, NGF can influence (1) the process of myelination/internodal length (Urschel and Hulsebosch, 1990), (2) fiber diameter (Gold et al., 1991), and (3) expression or properties of ion channels (Black et al., 1997; Fjell et al., 1999) (see below).

In $A \alpha / \beta$ neurons, the remarkable similarity in the relationships of trkA and Nav1.8 expression with AP variables is consistent with the hypothesis that trkA availability limits NGF uptake and thus limits the influence of NGF on Nav1.8 expression, which in turn influences AP variables. This view is supported by previous reports of (1) a contribution of Nav1.8 to AP overshoot/ height and AP duration in nociceptive DRG neurons (Renganathan et al., 2001; Djouhri et al., 2003b), (2) modulation of Nav1.8 expression by NGF (Black et al., 1997; Dib-Hajj et al., 1998a), and (3) reduction of the influence of NGF on Nav1.8 mRNA expression by trkA antagonists (Fjell et al., 1999). The present correlation of Nav1.8 intensity with trkA intensity in individual $\mathrm{A} \alpha / \beta$ nociceptors also supports this hypothesis. Other $\mathrm{Na}^{+}$channel subtypes could possibly contribute to trkA influences on electrophysiological properties in $A \alpha / \beta$ nociceptors. Nav1.9 is likely to be less important than Nav1.8, because Nav1.9 expression levels in these neurons is low (Dib-Hajj et al., 1998b;
Fang et al., 2002), and, unlike Nav1.8, its intensity is not correlated with AP duration, AP height, or AP overshoot in $\mathrm{A} \alpha / \beta$ neurons (this paper). The lack of correlation of Nav1.9 intensity with trkA intensity in these neurons is consistent with the view that NGF does not strongly modulate Nav1.9 expression (Fjell et al., 1999). Nav1.7 is also regulated by NGF (Gould et al., 2000); in guinea pigs, Nav1.7 intensity is correlated with AP duration in $\mathrm{A} \alpha / \beta$ neurons, but its expression is relatively low in $\mathrm{A} \alpha / \beta$ nociceptors (Djouhri et al., 2003a). Thus, although we cannot exclude a contribution of other NGF-regulated $\mathrm{Na}^{+}$channels, the similarities in expression patterns between Nav1.8 and trkA are indicative of an important role for Nav1.8 in the trkA-related electrophysiological properties of $\mathrm{A} \alpha / \beta$ nociceptors.

\section{Lack of correlations of trkA with C-fiber neuron electrophysiology}

The absence of correlations between trkA expression and electrophysiological properties in C-fiber nociceptors could reflect the presence of other influences, which may dilute the observable effects of NGF on relevant pathways in these neurons. GDNF is likely to be one such influence. The generally greater expression of GDNF receptor components in small than large DRG neurons (Bennett et al., 1998) suggests a greater GDNF influence. This GDNF influence is reported in small DRG neurons with strong IB4 binding but not (or less) in those with strong trkA expression, which are NGF dependent (Bennett et al., 1998). After axotomy, Nav1.8 [which is expressed in both these small neuron populations (Benn et al., 2001)] can be upregulated by both NGF and GDNF, whereas Nav1.9 (expressed mainly in IB4-binding neurons) is upregulated mainly by GDNF; thus, the influences of $\mathrm{NGF}$ and GDNF on $\mathrm{Na}^{+}$channel expression and therefore electrophysiological properties are likely to differ in different populations of small DRG neurons (Fjell et al., 1999; Cummins et al., 2000).

To be functional, Nav1.8 needs to be inserted into the membrane. The density of functional Nav1.8 channels in the membrane is increased by annexin $11 / \mathrm{p} 11$, which is upregulated by NGF-trkA stimulation (Okuse et al., 2002), and is decreased by clathrin-associated protein-1A (CAP-1A), a selective linker between Nav1.8 and clathrin, which enables removal of the channel from the membrane (Liu et al., 2005). Because both p11 mRNA and CAP-1A protein are more highly expressed in small DRG neurons (Okuse et al., 2002; Liu et al., 2005), their influence may be greater in small than large DRG neurons.

Thus, in small DRG neurons with C fibers, the likely influence of factors other than NGF, such as GDNF, on $\mathrm{Na}^{+}$channel expression, including Nav1.8, in different subgroups may contribute to the lack of correlation between trkA and Nav1.8 levels; furthermore, different (perhaps more complex or over-riding) influences of other regulatory proteins in small neurons may contribute to the lack of correlation of Nav1.8 expression with electrophysiological properties in C-fiber neurons. In contrast, in $\mathrm{A} \alpha / \beta$ nociceptors, there may be a relative lack of influences from trophic factors other than NGF on these electrophysiological properties that allows the influence of trkA levels on such properties to be detectable.

\section{Conclusions}

In conclusion, most somatic afferent nociceptors in DRGs, including those with $A \alpha / \beta$ fibers, show strong trkA expression. This should help with discrimination of nociceptors from other DRG neurons. In $A \alpha / \beta$ nociceptive neurons, relationships be- 
tween the nociceptive electrophysiological phenotype, trkA, and Nav1.8 expression levels are consistent with their electrophysiological properties being influenced by Nav1.8 expression that is in turn regulated by NGF, the levels of which are controlled/limited in each neuron by the amount of available trkA.

\section{References}

Averill S, McMahon SB, Clary DO, Reichardt LF, Priestley JV (1995) Immunocytochemical localization of trkA receptors in chemically identified subgroups of adult rat sensory neurons. Eur J Neurosci 7:1484-1494.

Barbacid M (1994) The Trk family of neurotrophin receptors. J Neurobiol 25:1386-1403.

Benn SC, Costigan M, Tate S, Fitzgerald M, WoolfCJ (2001) Developmental expression of the TTX-resistant voltage-gated sodium channels Nav1.8 (SNS) and Nav1.9 (SNS2) in primary sensory neurons. J Neurosci 21:6077-6085.

Bennett DL, Dmietrieva N, Priestley JV, Clary D, McMahon SB (1996) trkA, CGRP and IB4 expression in retrogradely labelled cutaneous and visceral primary sensory neurones in the rat. Neurosci Lett 206:33-36.

Bennett DL, Michael GJ, Ramachandran N, Munson JB, Averill S, Yan Q, McMahon SB, Priestley JV (1998) A distinct subgroup of small DRG cells express GDNF receptor components and GDNF is protective for these neurons after nerve injury. J Neurosci 18:3059-3072.

Black JA, Langworthy K, Hinson AW, Dib-Hajj SD, Waxman SG (1997) NGF has opposing effects on $\mathrm{Na}^{+}$channel III and SNS gene expression in spinal sensory neurons. NeuroReport 8:2331-2335.

Burgess PR, Perl ER (1967) Myelinated afferent fibres responding specifically to noxious stimulation of the skin. J Physiol (Lond) 190:541-562.

Casaccia-Bonnefil P, Gu C, Khursigara G, Chao MV (1999) p75 neurotrophin receptor as a modulator of survival and death decisions. Microsc Res Tech 45:217-224.

Clary DO, Reichardt LF (1994) An alternatively spliced form of the nerve growth factor receptor TrkA confers an enhanced response to neurotrophin 3. Proc Natl Acad Sci USA 91:11133-11137.

Cummins TR, Black JA, Dib-Hajj SD, Waxman SG (2000) Glial-derived neurotrophic factor upregulates expression of functional SNS and $\mathrm{NaN}$ sodium channels and their currents in axotomized dorsal root ganglion neurons. J Neurosci 20:8754-8761.

Dib-Hajj SD, Black JA, Cummins TR, Kenney AM, Kocsis JD, Waxman SG (1998a) Rescue of alpha-SNS sodium channel expression in small dorsal root ganglion neurons after axotomy by nerve growth factor in vivo. J Neurophysiol 79:2668-2676.

Dib-Haij SD, Tyrrell L, Black JA, Waxman SG (1998b) NaN, a novel voltage-gated $\mathrm{Na}$ channel, is expressed preferentially in peripheral sensory neurons and down-regulated after axotomy. Proc Natl Acad Sci USA 95:8963-8968.

Djouhri L, Lawson SN (2001) Increased conduction velocity of nociceptive primary afferent neurons during unilateral hindlimb inflammation in the anaesthetised guinea-pig. Neuroscience 102:669-679.

Djouhri L, Lawson SN (2004) Abeta-fiber nociceptive primary afferent neurons: a review of incidence and properties in relation to other afferent A-fiber neurons in mammals. Brain Res Brain Res Rev 46:131-145.

Djouhri L, Bleazard L, Lawson SN (1998) Association of somatic action potential shape with sensory receptive properties in guinea-pig dorsal root ganglion neurones. J Physiol (Lond) 513:857-872.

Djouhri L, Dawbarn D, Robertson A, Newton R, Lawson SN (2001) Time course and nerve growth factor dependence of inflammation-induced alterations in electrophysiological membrane properties in nociceptive primary afferent neurons. J Neurosci 21:8722-8733.

Djouhri L, Newton R, Levinson SR, Berry CM, Carruthers B, Lawson SN (2003a) Sensory and electrophysiological properties of guinea-pig sensory neurones expressing $\mathrm{Na}(\mathrm{v}) 1.7(\mathrm{PN} 1) \mathrm{Na}(+)$ channel alpha subunit protein. J Physiol (Lond) 546:565-576.

Djouhri L, Fang X, Okuse K, Wood JN, Berry CM, Lawson S (2003b) The TTX-resistant sodium channel Nav1.8 (SNS/PN3): expression and correlation with membrane properties in rat nociceptive primary afferent neurons. J Physiol (Lond) 550:739-752.

Fang X, Djouhri L, Black JA, Dib-Hajj SD, Waxman SG, Lawson SN (2002) The presence and role of the tetrodotoxin-resistant sodium channel $\mathrm{Na}(\mathrm{v}) 1.9(\mathrm{NaN})$ in nociceptive primary afferent neurons. J Neurosci 22:7425-7433.
Fjell J, Cummins TR, Dib-Hajj SD, Fried K, Black JA, Waxman SG (1999) Differential role of GDNF and NGF in the maintenance of two TTXresistant sodium channels in adult DRG neurons. Brain Res Mol Brain Res 67:267-282.

Fjell J, Hjelmstrom P, Hormuzdiar W, Milenkovic M, Aglieco F, Tyrrell L, Dib-Hajj S, Waxman SG, Black JA (2000) Localization of the tetrodotoxin-resistant sodium channel $\mathrm{NaN}$ in nociceptors. NeuroReport 11:199-202.

Gerke MB, Plenderleith MB (2001) Binding sites for the plant lectin Bandeiraea simplicifolia I-isolectin $\mathrm{B}(4)$ are expressed by nociceptive primary sensory neurones. Brain Res 911:101-104.

Goedert M, Otten U, Hunt SP, Bond A, Chapman D, Schlumpf M, Lichtensteiger W (1984) Biochemical and anatomical effects of antibodies against nerve growth factor on developing rat sensory ganglia. Proc Natl Acad Sci USA 81:1580-1584

Gold BG, Mobley WC, Matheson SF (1991) Regulation of axonal caliber, neurofilament content, and nuclear localization in mature sensory neurons by nerve growth factor. J Neurosci 11:943-955.

Gould III HJ, Gould TN, England JD, Paul D, Liu ZP, Levinson SR (2000) A possible role for nerve growth factor in the augmentation of sodium channels in models of chronic pain. Brain Res 854:19-29.

Kashiba H, Noguchi K, Ueda Y, Senba E (1995) Coexpression of trk family members and low-affinity neurotrophin receptors in rat dorsal root ganglion neurons. Brain Res Mol Brain Res 30:158-164.

Kashiba H, Ueda Y, Senba E (1996) Coexpression of preprotachykinin-A, alpha-calcitonin gene-related peptide, somatostatin, and neurotrophin receptor family messenger RNAs in rat dorsal root ganglion neurons. Neuroscience 70:179-189.

Lawson SN (2002) Phenotype and function of somatic primary afferent nociceptive neurones with C-, Adelta- or Aalpha/beta-fibres. Exp Physiol $87: 239-244$.

Lawson SN, Waddell PJ (1991) Soma neurofilament immunoreactivity is related to cell size and fibre conduction velocity in rat primary sensory neurons. J Physiol (Lond) 435:41-63.

Lawson SN, Harper AA, Harper EI, Garson JA, Anderton BH (1984) A monoclonal antibody against neurofilament protein specifically labels a subpopulation of rat sensory neurones. J Comp Neurol 228:263-272.

Lawson SN, Crepps BA, Perl ER (1997) Relationship of substance P to afferent characteristics of dorsal root ganglion neurones in guinea-pig. J Physiol (Lond) 505:177-191.

Lawson SN, Crepps B, Perl ER (2002) Calcitonin gene-related peptide immunoreactivity and afferent receptive properties of dorsal root ganglion neurones in guinea-pigs. J Physiol (Lond) 540:989-1002.

LePecq JB, Paoletti C (1967) A fluorescent complex between ethidium bromide and nucleic acids. Physical-chemical characterization. J Mol Biol 27:87-106.

Lewin GR, Ritter AM, Mendell LM (1992) On the role of nerve growth factor in the development of myelinated nociceptors. J Neurosci 12:1896-1905.

Li L, Deng YS, Zhou XF (2000) Downregulation of TrkA expression in primary sensory neurons after unilateral lumbar spinal nerve transection and some rescuing effects of nerve growth factor infusion. Neurosci Res 38:183-191.

Liu C, Cummins TR, Tyrrell L, Black JA, Waxman SG, Dib-Hajj SD (2005) CAP-1A is a novel linker that binds clathrin and the voltage-gated sodium channel $\mathrm{Na}(\mathrm{v}) 1.8$. Mol Cell Neurosci 28:636-649.

Lu J, Zhou XF, Rush RA (2001) Small primary sensory neurons innervating epidermis and viscera display differential phenotype in the adult rat. Neurosci Res 41:355-363.

Mendell LM (1999) Neurotrophin action on sensory neurons in adults: an extension of the neurotrophic hypothesis. Pain Suppl 6:S127-S132.

Molliver DC, Radeke MJ, Feinstein SC, Snider WD (1995) Presence or absence of TrkA protein distinguishes subsets of small sensory neurons with unique cytochemical characteristics and dorsal horn projections. J Comp Neurol 361:404-416.

Okuse K, Malik-Hall M, Baker MD, Poon WY, Kong H, Chao MV, Wood JN (2002) Annexin II light chain regulates sensory neuron-specific sodium channel expression. Nature 417:653-656.

Renganathan M, Cummins TR, Waxman SG (2001) Contribution of 
$\mathrm{Na}(\mathrm{v}) 1.8$ sodium channels to action potential electrogenesis in DRG neurons. J Neurophysiol 86:629-640.

Ritter AM, Lewin GR, Kremer NE, Mendell LM (1991) Requirement for nerve growth factor in the development of myelinated nociceptors in vivo. Nature 350:500-502.

Stewart WW (1978) Functional connections between cells as revealed by dye-coupling with a highly fluorescent napthalimide tracer. Cell 14:741-759.

Urschel BA, Hulsebosch CE (1990) Schwann cell-neuronal interactions in the rat involve nerve growth factor. J Comp Neurol 296:114-122.

Verge VM, Richardson PM, Wiesenfeld-Hallin Z, Hokfelt T (1995) Differential influence of nerve growth factor on neuropeptide expression in vivo: a novel role in peptide suppression in adult sensory neurons. J Neurosci 15:2081-2096.

Whitaker JE, Haugland RP, Moore PL, Hewitt PC, Reese M, Haugland RP (1991) Cascade blue derivatives: water soluble, reactive, blue emission dyes evaluated as fluorescent labels and tracers. Anal Biochem 198:119-130.

Wiesmann C, de Vos AM (2001) Nerve growth factor: structure and function. Cell Mol Life Sci 58:748-759.

Zwick M, Davis BM, Woodbury CJ, Burkett JN, Koerber HR, Simpson JF, Albers KM (2002) Glial cell line-derived neurotrophic factor is a survival factor for isolectin B4-positive, but not vanilloid receptor 1-positive, neurons in the mouse. J Neurosci 22:4057-4065. 